\title{
ENSAIO SOBRE A PERCEPÇÃO DA CRIANÇA PEQUENA COMO CATEGORIA ESTÉTICA EM WALTER BENJAMIN
}

\author{
Fernanda Ferreira de Oliveira
}

\begin{abstract}
RESUMO
Este ensaio trata da relação entre o estado de percepção da criança pequena como categoria estética em alguns dos primeiros escritos de Walter Benjamin relacionados à estética, infância, livros, brincadeiras, imaginação. A experiência é um tema também abordado, no sentido de trazer para reflexão como a experiência infantil se constitui por meio da brincadeira, da fantasia e do sensório-perceptivo.
\end{abstract}

Palavras-chave: Infância. Categoria. Experiência Estética. Criança Pequena.

\section{ESSAY ON THE PERCEPTION OF THE SMALL CHILD AS AESTHETIC CATEGORY IN WALTER BENJAMIN}

\begin{abstract}
This essay deals with the relation between the state of perception of the small child as an aesthetic category in some of Walter Benjamin's earliest writings related to aesthetics, childhood, books, games, imagination. Experience is also addressed in the sense of bringing to reflection how the infantile experience is constituted by play, fantasy and sensory-perceptive.
\end{abstract}

Keywords: Childhood. Category. Aesthetic Experience. Little child.

A categoria infância e estética não estão desprendidas em concepções benjaminianas, pois o corpo nesta perspectiva aprende aquilo que é proporcionado pela experiência (Erfahrung). É um pensamento que trata de educação voltada para a classe social, com conotação ético-política, mas também estética, porque diz respeito aos sentimentos, criatividade, corporalidade, poesia, imaginário, percepção, cidade, o valor da vida, as 
imagens potentes sobre a infância e suas convicções, sendo assim, infância e concepção estética estão vinculadas.

Nos escritos de Benjamin, estão presentes diversas "imagens" da infância seja pelo viés autobiográfico, pelo brinquedo, pela brincadeira, pela arte, pela pedagogia, pelos livros. E pensar a experiência estética da criança pequena a partir dos seus escritos, que de certa forma não está desprendida da dos adultos, é algo complexo, porque como se sabe a constituição de seus conceitos é um caleidoscópio 1.

O ensaio Brinquedos e jogos de Benjamin de 1928 (2009), que se tornou referência para muitos pesquisadores (SANTOS, 2013) para justificar a forma como experiência infantil se constitui, pelas categorias repetição, jogo e brincadeira. E a construção dessas categorias tem na ordem da história e da cultura algo importante, que diz respeito à brincadeira infantil e a presença das pessoas mais velhas:

[...] assim como o mundo da percepção infantil está impregnado em toda parte pelos vestígios da geração mais velha, com os quais as crianças se defrontam, assim também ocorre com seus jogos. É impossível construí-los em um âmbito da fantasia, no país feérico de uma infância ou arte puras. O brinquedo, mesmo quando não imita instrumentos dos adultos, é confronto, e, na verdade, não tanto a criança com os adultos, mas destes com as crianças (BENJAMIN, 2009, 96).

Além de apresentar uma perspectiva reflexiva de criança e infância, principalmente desmistificando a ideia de pureza e essência, e colocar em evidência a importância do papel do adulto, acrescentaria aquias palavras Lars Gunnarsson (1987): "as crianças aprendem mesmo quando os adultos não têm intenção de ensinar", ou seja, a mimese novamente perfaz o seu trabalho, de impregnar as ações das crianças de vestígios. Perfaz não de maneira superficial, a mimese como imitação/cópia, mas no campo da reelaboração, porque a criança ao reelaborar também elabora novas formas de lidar com o mundo. $E$ isto passa por uma formação perceptiva, em que a criança exercita sua capacidade de fazer semelhanças em relação às pistas e sinais demonstrados pelos adultos.

\footnotetext{
1 Ver em Silva (2013)

Doutoranda em Educação pela Universidade Metodista de Piracicaba (UNIMEP). Mestra em Educação (UNIMEP).Brasileira, residente em Piracicaba SP. Email: nandaferreira4@hotmail.com
} 
Em Brinquedos e jogos, Benjamin deixa evidente que em companhia do caráter mimético, presente nas brincadeiras infantis as quais configuram uns dos caminhos da experiência infantil, está presente a lei da repetição, que, para o autor, rege o mundo do jogo/brincadeira $(\text { Spiele })^{2}$, pois a criança retoma o fato vivido desde o início, mas nunca é igual, por este motivo é novo, ou seja, a criança volta a produzir na brincadeira toda a circunstância vivenciada. E o fazer sempre de novo converte a experiência em hábito, até mesmo as formas mais simples, comer, dormir, lavar-se, constituem-se à luz do jogo, isto é, apresentamse às crianças de maneira lúdica.

A tessitura da experiência infantil, constituída pelo ato da mimese, abre caminho para o desdobramento do conceito de experiência estética infantil em Benjamin, porque a capacidade mimética se coloca inclinada a reconhecer e realizar semelhanças, atribuindo sentido, para perceber a organização das coisas do mundo pela representação e expressão que são inerentes a esse processo (SCHLESENER, 2009).

Essa questão da mimese é tratada no ensaio $A$ doutrina das semelhanças $^{3}$, de 1933 (BENJAMIN, 1987), que, na perspectiva da produção dos sentidos pelas crianças, tem na relação das semelhanças o caminho pelo qual elas conhecem os arranjos temporais do adulto pela imitação, porque ao mesmo tempo em que imita, inventa.

$\mathrm{Na}$ esteira de Schlesener, cabe destacar que para Benjamin esse conceito está no cerne de seus escritos "como uma capacidade humana que concretiza a nossa inserção no mundo por meio da percepção e da linguagem" $(2009,149)$.

A capacidade mimética tem na brincadeira infantil sua maior expressão, porque os jogos infantis estão tomados pela mimese que vão além de uma simples imitação de pessoas, porque a criança ao brincar transfigura-se não somente em "comerciante ou professor, mas também em moinho de vento e trem" (BENJAMIN, 1985, 108) e para a maior parte dos adultos essa lógica passa despercebida. Nesse sentido, deve-se pensar a brincadeira infantil como um processo de interpretar e representar o que acontece em torno ao mesmo tempo em que é produto dessa adjacência, a partir dessa relação que a criança cria,

\footnotetext{
2 Nota do tradutor (p.102): Spiele no original pode ser traduzido tanto como jogo ou brincadeira.

${ }^{3}$ Com uma segunda versão no mesmo ano sob o título Sobre a faculdade mimética.
} 
elabora e produz coisas na exterioridade de acordo com seus interesses próprios.

Benjamin também aborda o brincar da criança nos ensaios Livros infantis antigos e esquecidos, de 1924, e em uma versão menor Canteiro de Obra de 1928 (1987), nos quais o autor vai acentuar o sentido do brinquedo na experiência da criança ao mesmo tempo em que faz uma crítica à visão linear das pessoas, em relação às formas como ocorrem essas brincadeiras e suas percepções. Como afirma Benjamin, essa postura, acaba fomentando uma das mais bolorentas especulações sobre a atividade infantil desde o lluminismo: a indústria de brinquedos pedagógicos.

Nesse sentido Benjamin realça que,

[...] a terra está cheia de substâncias puras e infalsificáveis capazes de despertar a atenção infantil. Substâncias extremamente específicas. As crianças, com efeito, têm um particular prazer em visitar oficinas onde se trabalha visivelmente com coisas. Elas se sentem atraídas irresistivelmente pelos detritos, onde quer que eles surjam na construção de casas, na jardinagem, na carpintaria, na confecção de roupas. Nesses detritos, elas reconhecem o rosto que o mundo das coisas assume para elas, e só para elas. Com tais detritos, não imitam o mundo dos adultos, mas colocam os restos e resíduos em uma relação nova e original. Assim, as próprias crianças constroem seu mundo de coisas, um microcosmo no macrocosmo (BENJAMIN, 1987, 237-238).

O que Benjamin nos leva a pensar é que no contexto da brincadeira se realiza a reprodução de situações, e mesmo os restos e objetos que pertencem inicialmente a uma determinada função, acomoda um novo sentido nas mãos das crianças numa relação sem fim de semelhança.

Com base nesse "representar que cria" da criança, Benjamin, de forma indireta, elabora correlações entre o brincar infantil e o fazer do artista em momentos diversos de seus escritos. De acordo com Damião (2014), esta relação é possível encontrar em alguns dos primeiros escritos de Benjamin relacionados à estética, seus escritos autobiográficos que tratam de temas sobre as cores e a fantasia, e sobre a obra de arte onde retoma alguns conceitos mesclando a ideia de percepção infantil.

No Fragmento intitulado A visão da criança da cor (1914-1915), Benjamin (1991, 110-112 apud SCHLESENER, 2009), evidencia que as cores têm algo de 
espiritual, no sentido alegórico, como se tivessem vontade própria e ao se misturarem constituem novas nuances de cores, convertendo a essência da substância em essência espiritual. Esse olhar também se volta para a imagem infantil na perspectiva da fantasia e percorre a alegria das crianças ao perceberem a transformação da mistura das cores na sua dinâmica passagem de tonalidade, como se fosse magia, com a multiplicidade de cores da bola de sabão.

Para Benjamin (1991), as crianças estão perceptivas com as combinações das cores na pintura, nas imagens, na lanterna mágica, elas (as cores) são impulso para a transformação do próprio objeto. Ou seja, o objeto de arte na percepção da criança tem potencial de mudança. Como afirma Schlesener, "Seu olhar não pousa sobre a obra para julgá-la segundo padrões, mas para perceber a diversidade de sentidos e as possíveis correspondências dadas nas cores" $(2009,152)$.

Para Damião (2014), esse fragmento benjaminiano juntamente com outro aforismo denominado O arco-íris. Diálogo sobre fantasia, de 1915, conecta aspectos da cor e fantasia à livre percepção sensorial infantil em oposição às formas friamente definidas, ou seja, as percepções primeiras e primárias da criança em contraposição a uma visão conceitual e do canônico artístico enraizado.

Esses conceitos que atravessam as ideias de Benjamin, e se apresentam como um tipo de percepção infantil e dizem respeito à experiência sensorial com as cores, está apoiada, de acordo com Brüggemann (2006 apud Damião, 2014), em várias fontes: a obra de Goethe: Doutrina das Cores; o romantismo alemão; Jean Paul; os pintores ligados ao expressionismo, como Kandinsky e Klee; e sua correspondência com Scholem, faz referências à discussão sobre a pintura do cubismo e de Chagall. Mas, foi entre outras tradições, principalmente em John Ruskin, que o autor encontrou a ideia que as relações estabelecidas com a obra de arte deveriam ser uma recuperação da percepção infantil, para a qual a percepção livre e não contaminada com as cores potencializaria a pintura, ou seja, as sensações visuais da obra de arte pelas sensações primeiras (DAMIÃO, 2014). Para além de uma visão comparativa de Benjamin, ele nos apresenta pistas de como se origina o processo de percepção estética infantil, quando 
salienta sobre as sensações das crianças frente às cores, que se realizam por meio dos sentidos: visão, tato, olfato, escuta, paladar.

A percepção infantil constituída pelas cores tem uma relação com o jogo e fantasia em Benjamin, pois a capacidade mimética inunda a relação da criança pequena com o mundo à medida que se reconhece com as coisas ou transformase no próprio objeto, por meio de "fazer como se", no tempo/espaço da brincadeira. Essa capacidade de produzir semelhança, na brincadeira infantil, se assemelha com as experiências com as cores no espaço do jogo de faz-deconta, onde o conjunto colorido recebe características diversas que advertem de sua natureza perfazendo o imaginário criador da criança pequena.

Essa experiência imaginativa da criança com as cores e imagens é retomada em dois textos de Benjamin, A visão do livro infantil, de 1926 e As cores presente em Infância em Berlinpor volta de 1900, obra de 1936. Os dois ensaios nos mostra uma visão de como a criança produz sua própria experiência estética, erigida a partir de sua sensibilidade, onde coisas diferentes se alinham numa lógica entre os elementos participantes do processo inventivo.

No primeiro texto benjaminiano mencionado encontramos as seguintes palavras em relação à ilustração dos livros infantis e sua aparência impressa: "as cores flutuam aladas sobre as coisas. Pois seu encanto não irradia do objeto colorido ou simplesmente da cor inanimada, mas sim da aparência colorida, do brilho colorido, da reverberação colorida" $(2002,80)$.

Essa forma de pensar a aparência da ilustração colorida, na perspectiva da percepção infantil benjaminiana, permeia o processo de criação, pois no contato com a gravura a criança constrói uma nova e própria narrativa.

\footnotetext{
Não são as coisas que saltam da página em direção à criança que as vai imaginando - a própria criança penetra nas coisas durante o contemplar, como nuvem que se impregna do esplendor colorido desse mundo do pictórico. Diante de seu livro ilustrado, a criança coloca em prática a arte dos taoistas consumados: vence a parede ilusória da superfície e, esgueirando-se por entre tecidos e bastidores coloridos, adentra um palco onde vive o conto maravilhoso. (BENJAMIN, 1926/2002, 69).
}

Diante desta exposição percebemos com mais clareza que a interpretação de Benjamin sobre a relação da criança com a ilustração, e pode 
se entender as diferentes formas de arte, apresenta-se como uma relação característica própria constituindo uma espécie particular de experiência com a arte. É uma relação de imersão na recepção da obra de arte e essa relação é uma experiência de aproximação do objeto artístico por meio de suas cores, formas, relações, incorporações, sensações, imitações construindo uma relação imaginativa com aquela.

No segundo ensaio (As Cores) Benjamin aprofunda sobre a questão da constituição do potencial imaginativo das crianças, e poeticamente expressa que a experiência da criança com as cores funde-se com a fantasia ao se misturar com as bolhas de sabão que como um viajante participa de um jogo com as cores até suas cúpulas estourarem. Essa experiência imaginativa se dá também com as histórias infantis em que a criança salta dentro das narrativas e explicita sua relação corpo- mente.

Trazer à tona esse tipo de percepção estética ou experiência estética infantil é um espaço de percepção constituída diferente do adulto, porque para a criança a recepção da obra de arte incialmente é novidade: são visões primeiras e primárias, sensações primeiras e percepções sensoriais, por outro lado, ela também é fantasia porque a criança diante da obra de arte mergulha, assim como Benjamin reporta-se, por várias vezes, à lenda do pintor chinês, que ao término de seu quadro, imergiu nele e desapareceu na paisagem. Como viajem na bolha de sabão em que seu passageiro joga com as cores.

A experiência estética infantil na esteira das percepções primeiras com a arte percorre as duas polaridades, aparência e jogo ${ }^{4}$, genuínas de sua formação em estado de harmonia para formação cultural da criança pequena. E perceber a imersão na obra de arte pelas crianças por meio da imaginação requer entender a constituição da forma infantil de recepção estética.

\section{REFERÊNCIAS}

\footnotetext{
${ }^{4}$ Sobre polaridade da arte ver em Oliveira (2017). 
BENJAMIN, Walter. A obra de arte na época de sua reprodutibilidade técnica. Tradução e notas Francisco De Ambrosis Pinheiro Machado. Porto alegre, Zourk, 2014.

Obras escolhidas. v. I: Magia e técnica: arte e política.

São Paulo: Brasiliense, 1985.

Brasiliense, 1987.

Obras escolhidas. v. II: Rua de Mão Única. São Paulo:

Obras escolhidas. v. III: Charles Baudelaire: um lírico no

auge do capitalismo. São Paulo: Brasiliense, 1989.

Paulo: Summus, 2009.

Reflexões: a criança, o brinquedo, a educação. São

Perspectiva, 1993.

; SCHOLEM. Gershom. Correspondência. São Paulo:

;Reflexões sobre a criança, o brinquedo e a educação.

Tradução Marcus Vinicius Mazzari. São Paulo: Duas Cidades; Editora 34, 2002.

DAMIÃO, Carla Milani. As cores da fantasia. In: Trama interdisciplinar. São

Paulo v. 5, n.2 p. 38-45, ago. 2014.

GUNNARSONN, Lars. A política de cuidado e educação infantil na Suécia. In: Rosember, Fulvia e Campos, Maria Malta. Creches e pré-escola no hemisfério norte. São Paulo, Cortez; Fundação Carlos Chagas, 1987, p. 5055.

SANTOS, Sandro Vinicius Sales dos.A gente vem brincar, colorir e até fazer atividade: a perspectiva das crianças sobre a experiência de frequentar uma instituição de Educação Infantil. Dissertação (Mestrado em educação). Faculdade de Educação UFMG,Belo Horizonte, 2013.

SCHLESENER, Anita Helena. Mímesis e infância: observações acerca da educação a partir de Walter Benjamin. In: Revista Filosofia Unisinos, Curitiba, v. 10, p. 148-156, mai/ago, 2009.

SILVA, Priscila Stuart da. Educação estética: corpo experiência e memória em Walter Benjamin. Dissertação (Mestrado em educação), Universidade Federal de Santa Catarina, Florianópolis, 2013.

OLIVEIRA. Fernanda Ferreira. Produção de sentidos e Experiência Estética na Educação Infantil. Dissertação (Mestrado em Educação), Universidade Metodista de Piracicaba, 2017. 